\title{
NOTAS SOBRE UN ADMINISTRATIVISTA: SABINO ALVAREZ-GENDIN Y BLANCO (1895-1983)
}

92:01

por

\section{Vicente de la Vallina Velarde}

El 30 de noviembre de 1983 fallecía en Madrid el Catedrático de Derecho administrativo Sabino AlvarEZ-Gendín y Blanco, quien durante más de cincuenta años cultivó con dedicación ejemplar esta parcela del Derecho público, junto con otros conocidos nombres, como los de García Oviedo, JoRdana de Pozas, etc.

Para los que hemos tenido la satisfacción de conocer al Profesor Alvarez-Gendin, primero como alumnos y después honrados con su amistad e incesante magisterio, en el más pleno sentido del vocablo, no resulta fácil condensar en unas líneas la vida y la obra de este autor, un hombre de profundas convicciones religiosas, que en la faceta que consideramos estudió y vivió con empeño la Administración pública en sus múltiples aspectos: como Secretario de Administración local en el Ayuntamiento de Oviedo (1925-1933), en cuyas dependencias llevó a cabo una interesante labor de organización administrativa, que le serviría de base para algunas publicaciones sobre el tema (1); en la Cátedra de Derecho administrativo de la Universidad ovetense (1933-1955), en la que fue maestro de

(1) Vid.: Registros y clasificación de documentos administrativos, Ed. Reus, Madrid, 1934, y "Clasificación y registro de documentos en Corporaciones locales», en Documentación Administrativa, 13, 1959, págs. 84 y sigs. 
sucesivas promociones de alumnos, que le recuerdan con afecto, gratitud y respeto (2); en el Rectorado de la expresada Universidad (1937-1951); como Parlamentario (1942-1951); en la Abogacía; en la Magistratura del Tribunal Supremo (1955-1967), y en el Instituto de Estudios de Administración Local, en el que impartió clases hasta el año 1975.

Nació en Avilés el 21 de marzo de 1895, en la calle de la Cámara, número 26, cursando los estudios de Bachillerato en el Colegio de los Hermanos de la Doctrina Cristiana, y después brillantemente la Licenciatura de Derecho en la Universidad de Oviedo, habiendo recibido la influencia importante de Adolfo PoSADA, conocido impulsor de los estudios político-administrativos de finales y principios de siglo, doctorándose en la Universidad Central de Madrid, con la calificación de sobresaliente, el 31 de mayo de 1920, con el trabajo realizado bajo la dirección de PoSADA sobre «Las Mancomunidades municipales» (1921), título expresivo de una de las parcelas que más atraería su atención, la Administración local, que encabezaría una larga lista de publicaciones, que entre libros, artículos de revistas y conferencias pasan del centenar, y que aun a riesgo de omitir alguna, enumeramos cronológicamente al final de estas notas en su memoria.

Amplió estudios en diversas Universidades extranjeras: París, Munich, Zurich y Milán; fue Profesor Auxiliar en la Universidad de Salamanca entre 1924-1925 e ingresa este último año en el Cuerpo Nacional de Secretarios de Administración Local, tomando posesión del cargo de Secretario del Ayuntamiento de Oviedo en mayo de 1925, después de un disputado concurso, en donde permanece hasta que en 1933 gana por oposición la Cátedra de Derecho administrativo de la Universidad de Santiago, siendo trasladado a la de Oviedo aquel mismo año, en donde inicia el curso académico 1933-34.

Posteriormente es nombrado Rector en 1937, cargo que desempeña hasta 1951, en que le sustituye el Profesor FERNANDEZ-MrRANDA Hevia. En este puesto desarrolla, como es bien sabido en la Región

(2) El 8 de julio de 1978 se descubrió una placa en el Departamento de Derecho administrativo de la Facultad de Derecho ovetense, con esta inscripción: «Seminario Sabino Alvarez-Gendín de Derecho administrativo».

Demostrativo de lo que se dice en el texto, vid., por ejemplo, L. ARce Monz6n: "Carta al Excmo. Sr. D. Sabino Alvarez-Gendin y Blanco", en Boletín de Información Municipal del Excmo. Ayuntamiento de Oviedo, 4/1977, abril, págs. 3-5.

Podemos citar aquí también las múltiples ocasiones en las que intervino dirigiendo trabajos de investigación, tesis doctorales en la Universidad o en los Cursos de Diplomados del Instituto de Estudios de Administración Local. 
asturiana, una gran labor orientada a la reconstrucción de la Universidad, en el más amplio sentido del término; su Rectorado fue unido no sólo al mantenimiento del Alma Mater ovetense, entonces cuestionada, sino también a un renacimiento de la misma: nuevas Facultades, Colegios Mayores, cursos de verano, revista de la Universidad, etc., volvieron a tener en ALVAREZ-GENDín y en la Junta de Gobierno que le asistía entusiastas valedores.

Por su cargo de Rector, y a partir de la Ley de 1942, fue Procurador en Cortes, y con este carácter participó activamente en la redacción de la Ley de Bases de Régimen local de 17 de julio de 1945, pronunciando el discurso de presentación de la misma ante la Cámara, en nombre de la Comisión dictaminadora de Gobernación (3).

El año 1946, a iniciativa suya y en colaboración con la Diputación Provincial de Oviedo, se crea el Instituto de Estudios Asturianos para fomentar el estudio de los valores culturales de la Región asturiana, del que fue primer Director y miembro de número hasta que por Decreto de 17 de junio de 1955 es nombrado Magistrado del Tribunal Supremo, por lo que pasa a la situación administrativa de supernumerario, como Catedrático de la Universidad, y quedando en el Instituto como Presidente de honor y miembro numerario perpetuo (4).

Ejerció sus funciones jurisdiccionales en la Sala 3. ${ }^{\mathrm{a}}$ del Tribunal Supremo hasta el año 1967, en que se jubila (5).

Entre sus títulos podríamos recordar los de Maestro de Primera Enseñanza (1946), Graduado Social (1948), Licenciado en Ciencias

(3) Vid. en Boletin del Colegio Nacional de Secretarios de Administración Local, 7, 1945, págs. 303 y sigs., el texto completo del discurso.

(4) El artículo 1.' de los Estatutos del Instituto de Estudios Asturianos, aprobados por la Diputación Provincial en sesión de 26 de junio de 1952 y por la Comisión Permanente del Patronato «José María Quadrado», del Consejo Superior de Investigaciones Científicas, dice así:

«El Instituto de Estudios Asturianos tiene por objeto el fomento y orientación de cuantos trabajos y estudios tiendan a conservar, elevar e incrementar el acervo cultural y artístico de la Region, en su aspecto típicamente asturianos.

En la reforma aprobada el 27 de abril de 1978, se completa el párrafo, en el sentido de «elevar e incrementar el acervo científico, cultural y artístico de la Región».

Siendo Director del Instituto, propuso en 1947 la tarea de «estudiar las Actas de la Junta del Principado de Asturias, existentes en el archivo de la Diputación Provincial, comenzando por su transcripción y publicación». Cfr. en Prólogo a las Actas de las Juntas y Diputaciones del Principado de Asturias, I, Oviedo, 1949, pág. XI, habiéndose editado siete volúmenes - 1949-1964-, que recogen las Actas referidas al período 1594 a 1672.

(5) Entre las primeras sentencias de las que fue ponente, encontramos las de 29 de septiembre, 8 y 11 de octubre de 1955 (Arz. 2.526, 2.797 y 2.808, de 1955), sobre materia financiera, y las últimas, correspondientes a 1967, de 15,16 y 23 de noviembre (Arz. 4.135, 4.207 y 4.315, de 1967), tenían relación con los Ministerios de Obras Públicas - transportes de viajeros por carretera- y Educación -Bellas Artes-. 
Políticas y Económicas (Sección de Económicas) por la Universidad de Madrid (1950), Miembro del Instituto Internacional de Ciencias Administrativas y Miembro correspondiente de la Real Academia de Ciencias Morales y Políticas. Por acuerdo de las respectivas Corporaciones locales, le fue concedido el título de Hijo Predilecto de Avilés y de Asturias e Hijo Adoptivo de Oviedo, y a propuesta de la Universidad, fue nombrado Rector honorario de la misma, en virtud de Orden ministerial de 4 de noviembre de 1966.

Estaba en posesión, entre otras, de las Grandes Cruces de Alfonso X el Sabio y de San Raimundo de Peñafort.

En un plano científico, cabría encuadrar al Profesor ALvarezGENDín en el grupo de estudiosos españoles de la ciencia del Derecho administrativo, que entre los autores del período de renovación de finales y principios de siglo: Adolfo Posada (de quien, como ya dijimos, fue discípulo), Santamarfa de Paredes, Antonio Royo-VILlanova, el P. GüENECHEA, GASCón y MARÍN y FERNÁNDEZ DE VELASco (1892-1920), sirve de generación puente, junto con otros conocidos cultivadores de esta disciplina: García Oviedo, JoRdANA DE Pozas, Segismundo Royo-Villanova, entre otros, a la más joven y floreciente escuela de administrativistas, que marcó la conocida renovación de estos estudios en España al filo de los años cincuenta (6).

En este campo, el Profesor Alvarez-Gendín creo que se ha sentido, en alguna manera, un modesto continuador de la obra realizada, por lo que en alguna ocasión ha calificado de «escuela asturiana de Derecho administrativo" (Posada Herrera, Adolfo Posada y Jesús ARIAS DE Velasco, que fue su maestro en las aulas de la Universidad de Oviedo), por los dos últimos antecesores en la Cátedra de Oviedo.

Aparte de la influencia que en él han tenido autores españoles como Posada Herrera, Colmeiro, Santamarfa de Paredes y especialmente A. Posada, que fue su maestro en los estudios del doctorado, a quien llama «el respetable maestro español señor PosADA» (7), hay que recordar su formación en las Universidades de París (1923-24), Munich (1928), Zurich (1930) y Milán (1935), en las que recibió la influencia de los autores de la época, especialmente

(6) Cfr. A Nieto: «Influencias extranjeras en la evolución de la ciencia española del Derecho administrativo», en Anales de la Universidad de La Laguna, III, 1965-66, La Laguna (Tenerife), págs. 43 y sigs.

(7) Cfr. en Regionalismo. Estudio general. El problema en Asturias, Oviedo, 1932, página 84 , nota 22. 
franceses; en este sentido, cabe señalar que fue pensionado por la Junta de Ampliación de Estudios para perfeccionar conocimientos en París, desde 1923 a 1924, y más tarde, el año 1930, fue también becado por la misma Junta para realizar estudios en Zurich. Consecuencia de estos contactos fueron las traducciones, de las que damos cuenta en el apartado 5, de las obras de Mirkine GuETzÉvitch y Fritz FLEINER, de Derecho constitucional y administrativo, respectivamente. Pero, en general, el Profesor Alvarez-Gendín, como los autores de la época, con la excepción de PoSADA, sigue la trayectoria de la doctrina francesa (8).

Trabajador infatigable, como se ha dicho, de lo que es fruto su extensa obra escrita, relacionada al final, que abarca un amplio campo, fundamentalmente en el plano jurídico, podríamos encuadrarla en los siguientes apartados:

1. Obras generales de Derecho administrativo.

2. Monografías jurídico-administrativas.

3. Estudios relativos a la Administración local.

4. Trabajos sobre temas de carácter regional.

5. Otros trabajos.

\section{Obras generales DE DERECho aDMinistrativo}

Resultado de sus estudios monográficos, de su experiencia docente y profesional y expresión, en fin, de una madurez fecunda, va elaborando sucesivamente con mayor extensión y profundidad, las obras generales de las que es autor.

Primero, su Manual de Derecho administrativo, que publica en 1941, dirigido sustancialmente a los alumnos, en el que sigue un método de carácter jurídico. "Así, pues —escribe en el proemio-, nuestra obra queda reducida a ser un modesto manual de principios, si bien éstos deducidos, dentro de un método rigurosamente jurídico, de la legislación dominante del país» (9), y en él define el Derecho administrativo como «la ciencia que estudia los principios que inspiran y las normas que regulan la organización, funciones y la jurisdicción administrativas»(10). Divide el Manual en dos partes: general y especial, en las que estudia en dieciséis capítulos

(8) Vid. S. Alvarez-GendfN: Manual de Derecho administrativo, Zaragoza, 1941, pág. 104.

(9) Cfr. Manual, cit., pág 7.

(10) Cfr. Manual, cit., pág. 83. 
los temas clásicos de nuestra disciplina: Administración, Derecho administrativo, fuentes, las personas de Derecho público, los órganos, el acto administrativo, los contratos administrativos (que él denomina públicos), la expropiación forzosa, etc. Propiamente se trata, dadas las materias que se estudian, de la llamada convencionalmente parte general en los programas de la asignatura.

En 1954 publica el Manual de Derecho administrativo español, en donde se recoge el Derecho positivo vigente a la sazón y que completaba el Manual del año 1941, «un libro mentor para estudiar los principios o fundamentos jurídico-positivos de nuestra disciplina" (11). De acuerdo con la definición de la asignatura dada por el autor, divide el libro en tres partes: "Organización», "Funciones y responsabilidad de la Administración» y «Garantías jurídicas de los administrados», con un total de 63 capítulos; obra que lleva un apéndice actualizando la legislación al año 1958 (Ley de Régimen Jurídico de la Administración del Estado de 1957, Ley de Expropiación Forzosa de 1954, Ley de Montes de 1957 y Ley Jurisdiccional de 1956).

Por último, entre 1958 y 1977 redacta su Tratado general de Derecho administrativo, en cuatro volúmenes, dedicados, respectivamente, a: «Parte general», «Derecho de la organización administrativa», "Parte especial o actividad administrativa», y el último, "Derecho procesal administrativo».

Es de observar, como ya adelantábamos, que esta obra general supone, por una parte, el desarrollo de sus Manuales de 1941 y 1954; por otra, tiene su base doctrinal en los estudios monográficos que sobre distintas materias ha ido desarrollando a través de una larga vida de estudio, y a los que nos referiremos seguidamente, $y$, por último, se recoge en ella una larga experiencia profesional, como el propio autor pone de relieve: ocho años de servicios a la Administración local, veintidós en la Cátedra, trece en el Tribunal Supremo, así como otras actividades relacionadas con la Administración pública, ejercicio de la Abogacía, Parlamentario en las Cortes, Rector de la Universidad en una etapa de plena reconstrucción, fundador y primer Director del Instituto de Estudios Asturianos, etc. Todo ello da a su obra, a mi modesto entender, un evidente valor, porque independientemente de que en ocasiones estemos o no de acuerdo con alguno de sus planteamientos, padezca la claridad expositiva o se observe un cierto descuido en la tarea de corrección

(11) Cfr. Manual de Derecho administrativo, Bosch, Barcelona, 1954, pág. 5. 
de pruebas, con las consigueintes erratas que se deslizan en el texto, fácilmente subsanables por lo demás, se recoge una rica experiencia que en Derecho administrativo tiene tanta importancia para evitar el riesgo de que quede reducido a un mero saber libresco, desconectado de la realidad. De alguna manera podemos recordar la afirmación de V. E. ORLANDo en su célebre prolusión en la Universidad de Palermo en enero de 1889, de acuerdo con el historicismo que profesaba: il diritto è vita: efficienza última del caràttere stòrico di un pòpolo, e dei sentimenti delle comunità (12), o más concretamente con Biondo BIONDI: "precisamente porque la justicia es algo concreto y expresión de la conciencia social colectiva, el jurista no puede recluirse en la torre de marfil de sus doctrinas, no puede abstraerse de la vida real...; conviene recordar siempre que todo problema jurídico, antes de ser tal, es un problema social y humano» (13).

\section{MONOGRAFIAS JURÍDICO-ADMINISTRATIVAS}

Desde que en 1921 publica su tesis doctoral sobre las Mancomunidades municipales, de la que nos ocuparemos en el apartado siguiente, podemos citar los siguientes estudios de los que fue autor:

- Expropiación forzosa. Su concepto jurídico (1928).

- Los contratos públicos. Doctrina y legislación (1934).

- El servicio público. Su teoría jurídico-administrativa (1944).

- El dominio público. Su naturaleza jurídica (1956).

- Teoría y práctica de lo contencioso-administrativo. Glosas a la nueva Ley (1960).

En relación con sus estudios sobre la expropiación forzosa, cabe señalar que la Real Academia de Ciencias Morales y Políticas le concedió en 1927 "Mención honorífica» en el Premio "Conde de Toreno", y en ellos sostiene la tesis de la expropiación no sólo por razones de utilidad pública frente a la utilidad privada, sino también por interés social frente a un interés individual (14).

Su obra sobre Los contratos públicos va precedida de un intere-

(12) Cfr. "I criterii tecnici per la ricostruzione giuridica del Diritto pubblico», en Archivio Giuridico, XLII, Pisa, 1889, pág. 123.

(13) Cfr. en Biondo Biondi: Arte y ciencia del Derecho, Ariel, Barcelona, 1953, página 149.

(14) Cfr. Expropiación forzosa. Su concepto juridico, Ed. Reus, Madrid, 1928, páginas 38-51. 
sante prólogo de L. JoRdANA DE POZAS, y en la misma el autor introduce esta terminología, que luego mantendrá, separándole de la generalidad de la doctrina, en la que distingue los contratos públicos de los privados de la Administración y reserva el nombre de contratos administrativos para todos aquellos en que la Administración es una de las partes, ya sean públicos, ya privados. Una actualización de este estudio será el publicado en 1969 con el título: Doctrina juridica de los contratos públicos del Estado y de la Administración local.

En El servicio público, después de referirse a la importancia del concepto dentro del Derecho administrativo, y considerar aquél como "coordinación o conjunto de actividades jurídico-administrativas, financieras y técnicas que organizan el Estado o las Corporaciones autárquicas, por pertenecer a su iniciativa, encaminadas a satisfacer económicamente necesidades públicas de una manera regular y continua» (15), estudia la clasificación y los elementos de la figura, para referirse después a los diversos sistemas de prestación, municipalización de servicios, relaciones jurídicas con los usuarios, etcétera. Como es usual en la obra del Profesor Alvarez-Gendín, esta monografía la incorpora en lo fundamental, actualizándola, al Tratado general (16).

El año 1956 publica su obra El dominio público. Su naturaleza jurídica, que ya había sido objeto de reflexión en varios trabajos de revista; recordemos, entre otros: «La naturaleza pública del dominio minero» (17); «El dominio público: su fundamento y naturaleza jurídica» (18), o "La naturaleza dominial pública de los edificios y de los bienes muebles» (19). Más tarde llevará esta materia al volumen III del Tratado, en ocho capítulos (20). Para el Profesor ALVAREZ-GENDín, el dominio público es «una forma de propiedad especial privilegiada de los Entes públicos, afectada a la utilidad pública, a un servicio público o al interés nacional, y entre tanto no sujeta a la enajenabilidad o prescriptibilidad, como la propiedad

(15) Cfr. El servicio público. Su teoría jurídico-administrativa, IEP, Madrid, 1944, página 21.

(16) Vid. tomo I, 1958, págs. 474 y sigs.

(17) Cfr. en Revista de la Universidad de Oviedo, 1941, págs. 41 y sigs.

(18) Cfr. en Estudios dedicados al Profesor Gascón y Marín en el cincuentenario de su docencia, IEAL, Madrid, 1952, págs. 259 y sigs.

(19) Cfr. en Estudios dedicados al Profesor García Oviedo, I, Universidad de Sevilla, 1954, págs. 17 y sigs.

(20) Cfr. en Tratado general de Derecho administrativo, III, Bosch, Barcelona, 1973, págs. 295 y sigs., caps. XXIII al XXX. 
privada, y aún favorecidos por otras notas» (21), y distingue, desde el punto de vista de su clasificación, una doble categoría: a) un dominio público común, así los bienes de uso público, como las carreteras, o los edificios destinados a un servicio público, y b) un dominio público especial (aguas, montes, minas, patrimonio nacional y los bienes comunales) (22).

Finalmente, en este grupo de monografías podríamos referirnos a su Teoría y práctica de lo contencioso-administrativo, que aparece en 1960, un momento especialmente interesante, ya que empieza a aplicarse la Ley de 27 de diciembre de 1956, en vigor desde el 27 de junio de 1957, según el acuerdo de la Sala de Gobierno del Tribunal Supremo de 18 de octubre de 1957, y el autor, desde su posición de Magistrado del Alto Tribunal, puede hacer uso de una experiencia "de casi un año de aplicación de la Ley» (23).

Este trabajo lo recoge ampliado en 1977, con aportaciones procedimentales y sistemas procesales extranjeros, en el tomo IV del Tratado general. Es de subrayar que en la Ley Jurisdiccional que nos ocupa, se hacen efectivas algunas de las posiciones doctrinales del autor y de otros juristas, en punto a especialización de la magistratura en la jurisdicción contencioso-administrativa, la judicialización de los órganos que la ejercitan, la ampliación del ámbito para la legitimación activa, la impugnación directa de las disposiciones legales, la unificación de los procesos contenciosos frente a las distintas esferas de la Administración y la regulación con carácter general de la figura del silencio administrativo, entre otras.

\section{Estudios Relativos a la Administración local}

Desde que el Profesor Alvarez-Gendín sigue, como ya se ha repetido, durante el curso 1919-20, los estudios del doctorado en la Universidad de Madrid, asistiendo a las clases de Derecho municipal comparado que impartía el insigne administrativista Adolfo Posada (24), de los que es fruto su tesis doctoral sobre las Manco-

(21) Cfr. El dominio público. Su naturaleza jurídica, Bosch, Barcelona, 1956, página 41.

(22) Cfr. El dominio público, cit., págs. 77 y sigs.

(23) Cfr. en Teoría y práctica de lo contencioso. Glosas a la nueva Ley, Bosch, Barcelona, 1960, pág. 207.

(24) En mayo de 1910 fue nombrado Adolfo Posada Catedrático de la recién creada asignatura de Derecho municipal comparado, Cátedra que habría de desempeñar hasta 1931, año en que se jubila.

«Mi Cátedra de Derecho municipal tenía que ser -afortunadamente- de pocos alumnos. Sentíame en ella transportado a la de Derecho político de mi Universidad 
munidades municipales (25), defendida el 31 de mayo de 1920, podemos decir que, posiblemente debido a la influencia del maestro, a quien llama «docto profesor» (26), su actividad profesional giraría especialmente en torno a la Vida local; recordemos sus ocho años de intenso trabajo en la Secretaría del Ayuntamiento de Oviedo, que indudablemente dejaron una huella en su formación (27); después, su participación en trabajos relacionados con la elaboración de la legislación local: así, fue Vocal de la Comisión encargada de redactar un Proyecto de Ley de Gobierno y Administración local, nombrada por el Ministerio de Interior, el 11 de noviembre de 1938, y después, miembro de la Comisión de Gobernación dictaminadora del Proyecto de Ley de Bases de Régimen local de 17 de julio de 1945 (28); también su actividad docente en la Escuela Nacional de Administración Local, que desarrollaría, como él mismo nos dice, hasta el año 1975 (29), y abarcándolo todo, las múltiples ocasiones en que su tarea investigadora se dirigió hacia esta esfera de la Administración pública. Pensemos en el volumen II de su Tratado, que dedica a los funcionarios de Administración local, «dignos compañeros míos», en su mayor parte consagrado a la Administración local -32 capítulos-, y, por último, los artículos de revista que tratan de temas locales, entre otros: «Estudio del Estatuto

de Oviedo. Como ocurriera en ésta, asistian a la de Derecho municipal de 14 a 20 alumnos y, en general, trabajadores, deseosos de aprender, interesados...».

«Tuve en esta Cátedra muchos discípulos, en el recto sentido de la palabra, que andando el tiempo habían de desempeñar y desempeñaron Cátedras universitarias...». Cfr. Adolfo Posada: Fragmentos de mis memorias, Universidad de Oviedo, 1983, páginas 338-339. Los subrayados en el original.

(25) Unos años antes, en 1914, el Catedrático de la Universidad de Zaragoza, José Gascón y Marín, había publicado su obra sobre Mancomunidades provinciales, que edita Reus.

(26) Cfr. Las Mancomunidades municipales, Ed. Reus, Madrid, 1921, pág. III.

(27) Como escribe el que fue Alcalde de Oviedo aquellos años, José María FerNÁNDEZ-LADREDA Y MENÉNDEZ-VALDÉs: «Pues bien, en aquellos momentos, inolvidables para mí por lo que se refiere a la capacidad, celo y afecto que me demostraron todos los empleados administrativos del Ayuntamiento, la figura del Secretario se agigant6 en términos insospechados; no solamente dirigía todos los trabajos preparatorios de los complicados expedientes que después debía estudiar el Pleno, sino que era mi constante asesor, informándome con lealtad y expresándose con tal sinceridad, aun en los casos en que conocía que su disconformidad había de producirme disgusto, que hoy, que el tiempo ha borrado tantas cosas, aún recuerdo emocionado las horas que GENDín y yo convivimos en la 'Casa municipal', uno y otro olvidándonos totalmente de todo lo que no fueran asuntos directamente relacionados con la administración y gestión de los asuntos del Concejo». Cfr. en el Prólogo a la obra de Sabino A. GeNDín: Regionalismo. Estudio general, cit., pág. 4.

(28) Ya hemos dicho que con tal carácter pronuncio el discurso ante la Cámara, en nombre de dicha Comisión; véase la nota 3.

(29) Cfr. S. ALVAREZ-GENDIN: Tratado general de Derecho administrativo, tomo IV, Bosch, Barcelona, 1977, pág. 7. 
municipal» (1924); «Reforma de la Administración provincial» (1941); «Reforma de la Administración municipal» (1943); «Contribución al estudio del Municipio en el siglo XVII» (1946); «Máxima descentralización, pero máxima responsabilidad» (1946); «La organización administrativa local en la República Federal alemana» (1955); «El nuevo régimen municipal de Barcelona» (1960), etc. El Profesor ALVAREZ-GENDíN, como es sabido, era un municipalista convencido, un localista, en el sentido técnico del término, partidario de la autonomía local, aunque por el momento histórico que le tocó vivir, sus ideas estuvieran, en parte, condicionadas por la situación circundante.

\section{TRabajos SOBRE TEMAS DE CARÁCTER REgIONAL}

En primer lugar, podríamos hacer mención a su interesante obra: Regionalismo. Estudio general. El problema en Asturias, que publica en 1932, ya expresada. Empieza refiriéndose al argumento en el Derecho federal suizo, comparando los Cantones de aquel país con las Regiones españolas; esta parte fue escrita en Zurich, cuando fue pensionado por la Junta de Ampliación de Estudios el año 1930. Pasa luego a estudiar el tema regional, con referencias a la Junta General del Principado de Asturias, al movimiento regionalista en España en relación con la Constitución de 1931 y los Estatutos regionales, para terminar con las bases para un posible Estatuto regional de Asturias.

Es partidario más bien de una descentralización administrativa que política para el Estatuto regional asturiano, organizando la Diputación regional de Asturias, como denomina al organismo político y administrativo de la Región, a base de una Asamblea de Diputados, un Consejo regional y un Presidente, e integrando en la Asamblea regional una triple representación: los Diputados de elección directa, los elegidos por las Corporaciones municipales y los designados por los Centros asturianos de América (30).

En diversas ocasiones se ocupó de la «Junta General del Principado de Asturias y de su Diputación", publicando con este título un trabajo en la Revista de la Universidad de Oviedo en 1940, asunto

(30) «Esta es la labor -escribe a propósito de cómo podría ser el Estatuto regional de Asturias- de un hijo de Asturias, que aporta un grano de arena para cimentar y levantar un sblido edificio regional, sin merma para el Estado español». Cfr. en Regionalismo. Estudio general, cit., pág. 97. 
sobre el que vuelve en 1949, al prologar las Actas de las Juntas y Diputaciones del Principado de Asturias (31).

Nos recuerda, con cita de Caveda y Nava, cómo la Junta General del Principado de Asturias fue «una verdadera representación de los Concejos de Asturias»; esta representación era corporativa: los Procuradores de la Junta los elegían los Concejos democráticamente, variando la representación de los pueblos en la Junta según su importancia y jurisdicción (32). Este dato nos alecciona sobre lo que fueron algunas de nuestras Entidades históricas intermedias entre el Municipio y el Estado, y el alcance de la naturaleza jurídica de las mismas, esto es, integradas por representantes de los Municipios, aparte de que pudieran estar representados en dichas Corporaciones otros intereses interlocales. Trasladando estas consideraciones al terreno de las Diputaciones Provinciales, éste podría ser uno de los sentidos cuando se dice que la Provincia, Entidad local, está «determinada por la agrupación de Municipios» (33).

$\mathrm{Y}$, por último, hace una serie de reflexiones sobre las autonomías regionales en varios artículos, en los que se insiste sobre los argumentos (34).

(31) Cfr. tomo I, Oviedo, 1949, págs. IX y sigs.

Sobre la Junta General, pronuncia el 15 de diciembre de 1977 una conferencia en el Centro Asturiano de Madrid, que lleva por título: «La Junta General del Principado de Asturias y la problemática asturiana» (cfr. en Boletín del Instituto de Estudios Asturianos, 93-94, 1978, págs. 3 y sigs., y años más tarde publica un trabajo sobre "El Principado de Asturias; su autonomía histórica», en Boletín del Instituto de Estudios Asturianos, 98, 1979, págs. 509 y sigs. Finalmente, también trata sobre el argumento en el Libro homenaje al Profesor J. Galvañ Escutia, Valencia, 1980, páginas 1 y sigs.

(32) Cfr. Regionalismo. Estudio general, cit., págs. 39 y sigs.

(33) Artículo 2. y concordantes de la Ley de Régimen local de 1955; artículo 45, II, de la derogada Ley Orgánica del Estado de 1967, y artículo 141, 1, de la Constitución de 1978.

Esta idea está recogida en mi trabajo La Provincia, Entidad local, en España, Oviedo, 1964, con Prólogo de S. Alvarez-Gendin.

(34) Así, «Problemas sobre descentralización y autonomía administrativa a nivel provincial o regional», en Revista de Derecho Administrativo y Fiscal, 31-32, 1972, páginas 7 y sigs.; «La Región», en Rivista Trimestrale di Diritto Pubblico, 2, 1973, páginas 710 y sigs., y, finalmente, "Reflexiones sobre las autonomías regionales», en Libro homenaje al Profesor Juan Galvañ Escutia, cit., págs. 1 y sigs.

A propósito de este último estudio, casi en el sentido literal del término, lo escribía en mayo de 1978, y, por tanto, a una edad avanzada, quiero dejar constancia de un hecho que demuestra al tiempo el espíritu de laboriosidad y de compañerismo que profesaba hacia todos sus colegas en la Cátedra, y en esta línea fue un asiduo colaborador en los distintos estudios-homenaje dedicados a ilustres Profesores: Gascón y Marín (1952), Garcfa Oviedo (1954), Legaz Lacambra (1960), Jordana de Pozas (1961), Pr y SUÑER (1962), LóPEZ Rodo (1972), Royo-VillaNova (1977) y GaLVAÑ EscuTIA (1980). Por razones de salud, ya no pudo participar en las últimas realizaciones: Homenaje a José Antonio García-Trevijano Fos, IEAL, Madrid, 1982, y Administración y Constitución. Estudios en homenaje al Profesor Mesa Moles, Presidencia del Gobierno, Madrid, 1982. 


\section{Otros trabajos}

Y para terminar estos apuntes sobre la vida y la obra del Profesor ALVAREZ-GENDIN, debemos aludir a otras publicaciones sobre distintas materias a las que prestó su infatigable atención.

Además de la traducción del francés de la obra de Mirkine GuETZÉvitch : Las modernas tendencias del Derecho constitucional (1934), y del alemán, la obra clásica de Fritz FLEINER: Instituciones de Derecho administrativo (1935), traducción ésta que JORDANA DE Pozas no dudó en calificar de "magistral» (35), podríamos referirnos a los estudios de carácter histórico - muchos sobre temas asturianos-, hacia los que siempre sintió una fuerte inclinación. Incluso en el campo del Derecho administrativo se sirvió de un método que él llama "mixto de carácter jurídico-histórico», siguiendo el camino iniciado ya por ColmeIro, que le sirve de "faro luminoso» (36). Entre éstos: El Cardenal Inguanzo: su vida y su obra (1943); Las Cortes españolas (1947); El movimiento cultural de Asturias, como antecedente del Instituto de Estudios Asturianos (1947); Cuaderno del Ordenamiento de Cortes del Reino de León (1948); El derecho de Asturias al voto en Cortes (1949); La capilla de Nuestra Señora de Begoña en Gijón (1949), discurso leído en el acto de recepción como miembro de número del Instituto de Estudios Asturianos; Documentos del Archivo del Ayuntamiento de Avilés (1951); Notas históricas sobre la Universidad de Oviedo (1952); Palacio Valdés y Asturias (1953); Un folleto interesante de Flórez Estrada (1955), y Notas históricas sobre los festejos de San Mateo y otros de Oviedo (1968) (37).

Por último, habiendo sido Profesor de Derecho sindical y corporativo en la Escuela Social de Oviedo, se acercó a estos problemas del mundo del trabajo en dos publicaciones: Del régimen del asalariado al de la participación laboral en la empresa (1952) y La participación laboral en la economía y administración de las empresas y la doctrina de los Pontífices (1962).

Debo poner fin a estas notas dedicadas con gratitud y respeto al Profesor Sabino Alvarez-GENDín y Blanco, administrativista astu-

(35) Cfr. en Prólogo a: Sabino A. Gendín: Los contratos públicos. Doctrina y legislación, Reus, Madrid, 1934, pág. XI.

(36) Cfr. en Manual de Derecho administrativo español, cit., 1954, págs. 5-6.

(37) Véanse estos trabajos en la reseña bibliográfica que por orden cronológico se incluye al final de estas notas. No se recogen los innumerables artículos sobre temas diversos aparecidos en la prensa nacional o local. 
riano, que llena una etapa entre 1921, fecha de su tesis doctoral sobre las Mancomunidades municipales, y 1977, en que aparece el tomo IV de su Tratado general de Derecho administrativo, dedicado al Derecho procesal administrativo. Más de cincuenta años de estudio, trabajo profesional en diversos campos, como se ha expresado, investigación y docencia, en el más amplio sentido del término; maestro de Derecho administrativo y de vida para los que fuimos sus discípulos, que supo anteponer a otras consideraciones -y esto me consta, no es una frase - una ejecutoria de bien, en línea con los conocidos juris praecepta del jurista romano: Honeste vivere, alterum non laedere, suum cuique tribuere (D., I, 1, 10, 1, UlPIANO, libro $1 .^{\circ}$ Reg.) (38).

\section{OBRA ESCRITA DEL PROFESOR ALVAREZ-GENDIN}

1. «Las Mancomunidades municipales» (tesis doctoral), Madrid, 1921, y en RCJS, 4, 1921, págs. 20 y sigs. y 161 y sigs.

2. «La responsabilidad ministerial», en $R G L J, 1923$, págs. 26 y sigs.

3. «Estudio del Estatuto municipal», en $R G L J, 1924$, págs. 687 y sigs.

4. «Teoría general de las fuentes del Derecho y consideración especial de las de Derecho públicon, en $R C J S, 6,1924$, págs. 67 y sigs., 137 y sigs. y 445 y sigs.

5. Teoría general de las fuentes del Derecho, Reus, Madrid, 1925.

6. «Indemnización de daños y perjuicios a los Secretarios suspensos o destituidos indebidamente», en $R G L J, 1927$, págs. 550 y sigs.

7. Expropiación forzosa. Su concepto jurídico, Reus, Madrid, 1928.

\section{Abreviaturas utilizadas}

AAMN = Anales de la Academia Matritense del Notariado.

BCNS = Boletín del Colegio Nacional de Secretarios, Interventores y Depositarios de Administración Local.

BIDEA = Boletin del Instituto de Estudios Asturianos.

$\mathrm{DA}=$ Documentación Administrativa.

RAP = Revista de Administración Pública.

RCDI = Revista Critica de Derecho Inmobiliario.

RCJS = Revista de Ciencias Juridicas y Sociales.

RDAF $=$ Revista de Derecho Administrativo y Fiscal.

RDPub. = Revista de Derecho Público.

REVL = Revista de Estudios de la Vida Local.

RFDM = Revista de la Facultad de Derecho Universidad de Madrid.

RFDO = Revista de la Facultad de Derecho Universidad de Oviedo.

RGLJ = Revista General de Legislación y Jurisprudencia.

RIDC = Revista del Instituto de Derecho Comparado.

RISA = Revue Internationale de Sciences Administratives.

RTDP = Rivista Trimestrale di Diritto Pubblico.

RUO = Revista de la Universidad de Oviedo.

(38) Cfr. Corpus Iuris Civilis, I, 21:" ed., Weidmannos, 1970, pág. 29. 
8. «Policía de costumbres y legislación española vigente en materia de inmoralidad públican, en $R G L J, 1928$, págs. 691 y sigs.

9. «La concesión y el contrato de Derecho público», en $R G L J, 1930$, páginas 423 y sigs.

10. Aglomeraciones urbanas y ensanche de poblaciones, Publicaciones de la Unión de Municipios, 1930.

11. «Federalismo y autonomismo", en RDPub., I, 1932, págs. 167 y sigs.

12. Regionalismo. Estudio general. El problema en Asturias, Oviedo, 1932.

13. «El voto de confianza en la Constitución española», en $R G L J, 1933$, páginas 687 y sigs.

14. «El concepto de Derecho administrativo», en $R G L J, 1934$, págs. 403 y sigs.

15. Los contratos públicos. Doctrina y legislación, Reus, Madrid, 1934.

16. Registros y clasificaciones de documentos administrativos, Reus, Madrid, 1934.

17. «El órgano gestor del Municipio», en RGLJ, 1935, págs. 321 y sigs., y 1936, páginas 26 y sigs., Reus, Madrid, 1936.

18. "Nociones sobre la jurisdicción contencioso-administrativa", en RDPub., 4, 1935, págs. 392 y sigs., y 5, 1936, págs. 1 y sigs. y 65 y sigs.

19. Los Estados modernos totalitarios, Publicaciones de la Universidad de Oviedo, 1938.

20. Teoría sobre la resistencia al Poder público. El caso español, Oviedo, 1939.

21. La Junta General del Principado de Asturias y su Diputación, Publicaciones de la Universidad de Oviedo, 1940.

22. Problemas suscitados por la guerra en materia de edificación y reconstrucción de ciudades, Publicaciones de la Universidad de Oviedo, 1940.

23. Manual de Derecho administrativo, Librería General, Zaragoza, 1941.

24. «La Ley especial de los Municipios adoptados», en RUO, 1940, páginas 122 y sigs.

25. "Limitaciones a la propiedad acordadas por los Ayuntamientos", en $R C D I, 1940$, págs. 36 y sigs.

26. «Naturaleza pública del dominio minero», en RUO, 1941, págs. 31 y sigs.

27. Reforma de la Administración provincial, Oviedo, 1941.

28. "Fuentes del Derecho», en $R F D M, 8-11,1942$, págs. 68 y sigs.

29. «La organización municipal en los Estados totalitarios», en REVL, 3, 1942, págs. 1 y sigs.

30. Teoría jurídica sobre la propiedad minera, Oviedo, 1942.

31. Reforma de la Administración municipal, Oviedo, 1943.

32. El Cardenal Inguanzo: su vida y su obra, Publicaciones de la Universidad de Oviedo, 1943.

33. "El régimen administrativo según Posada Herrera», en Centenario de los iniciadores de la ciencia jurídico-administrativa española, Madrid, 1944, págs. 41 y sigs.; en $R E V L, 14,1944$, págs. 224 y sigs., y en $R U O$, 24, 1944, págs. 5 y sigs., y 27-28, 1945, págs. 5 y sigs.

34. Concepto católico del Estado y de la Justicia, SAETA, Madrid, 1944.

35. El servicio público. Su teoría jurídico-administrativa, IEP, Madrid, 1944. 
36. «Glosas a la Ley de 18 de marzo de 1944 sobre reforma de la jurisdicción contencioso-administrativa», en RUO, 23-24, 1944, págs. 991 y sigs.

37. "La competencia municipal según la nueva Ley de Bases», en $R E V L, 22$, 1945, págs. 589 y sigs.

38. «Discurso pronunciado en nombre de la Comisión dictaminadora de Gobernación con motivo de la presentación por el Gobierno a las Cortes de la Ley de Bases de Régimen local», en BCNS, 7, 1945, págs. 303 y sigs.

39. «Garantías jurídicas de los ciudadanos frente a la Administración local», en $R E V L, 24,1945$, págs. 951 y sigs.

40. «Autonomía administrativa y económica en la nueva Ley de Bases de Régimen local», en Estudios de Administración local, Oviedo, 1946, páginas 77 y sigs.

41. «Contribución al estudio del Municipio en el siglo xvII», en Estudios de Administración local, Oviedo, 1946, págs. 3 y sigs., y en RUO, 33-34, 1946, páginas 5 y sigs.

42. «iMáxima descentralización, pero máxima responsabilidad!», en $R E V L$, 29, 1946, págs. 707 y sigs.

43. Las Cortes españolas, Oviedo, 1947.

44. Casos prácticos de Derecho administrativo, Oviedo, 1947.

45. «Jovellanos didáctico», en $B I D E A, 1,1947$, págs. 3 y sigs.

46. «EI movimiento cultural en Asturias, como antecedente del Instituto de Estudios Asturianos", en BIDEA, 2, 1947, págs. 3 y sigs.

47. «Cuaderno del Ordenamiento de Cortes del Reino de León», en BIDEA, 3, 1948, págs. 27 y sigs.

48. "Contribución al estudio de la Administración estatal española en los siglos XVI y XVII", en RUO, 1948, págs. 5 y sigs.

49. «Naturaleza pública del dominio minero. Problemas jurídico-privados que plantea la transmisión de concesiones», en $A A M N$, IV, 1948, páginas 411 y sigs.

50. «Contestación al discurso de J. Fernández Buelta de ingreso en el Instituto de Estudios Asturianos», en $B I D E A, 4,1948$, págs. 103 y sigs.

51. «La Ley de 17 de julio de 1948 sobre competencias», en $R E V L, 44,1949$, páginas 161 y sigs.

52. La Administración española en el Protectorado de Marruecos, plazas de soberania y colonias de Africa, IEA, Madrid, 1949.

53. Prólogo a las Actas de las Juntas y Diputaciones del Principado de Asturias, I, Oviedo, 1949, págs. XI y sigs.

54. «El derecho de Asturias al voto en Cortes», en BIDEA, 7, 1949, págs. 103 y sigs.

55. La capilla de Nuestra Señora de Begoña en Gijón, discurso de ingreso en el Instituto de Estudios Asturianos, Oviedo, 1949.

56. Los judios en el mundo y en España, discurso de apertura del curso académico 1949-50, Oviedo, 1949.

57. «Doctrina política del P. Vitoria y del P. Suárez», en RFDO, 1949, páginas 115 y sigs., y 1950, págs. 5 y sigs.

58. «Colmeiro historiador», en Estudios juridico-administrativos en honor de Colmeiro, Santiago, 1950, págs. 11 y sigs. 
59. «Proyección del Derecho público sobre el Derecho privado», en $R E V L$, 50, 1950, págs. 161 y sigs.

60. «La nueva Ley de Régimen local. Innovaciones y aclaraciones a la Ley de Bases», en $R E V L, 57,1951$, págs. 345 y sigs., y 58, 1951, págs. 546 y sigs.

61. «Documentos del archivo del Ayuntamiento de Avilés», en $B I D E A, 12$, 1951, págs. 91 y sigs.

62. El dominio público: su fundamento y naturaleza jurídica», en Estudios dedicados al Profesor Gascón y Marín en el cincuentenario de su docencia, IEAL, Madrid, 1952, págs. 259 y sigs.

63. Del régimen del asalariado al de la participación laboral en la empresa, Oviedo, 1952.

64. "Notas históricas sobre la Universidad de Oviedo", en $B I D E A, 15,1952$, páginas 3 y sigs.

65. «Acción popular y recursos administrativos contra los actos de la Administración local», en $R A P, 11,1953$, págs. 221 y sigs.

66. «Palacio Valdés y Asturias», en BIDEA, 19, 1953, págs. 479 y sigs.

67. Manual de Derecho administrativo español, Bosch, Barcelona, 1954, con Apéndice de 1958.

68. «Naturaleza dominial pública de los edificios y de los bienes muebles», en Estudios dedicados al Profesor Garcia Oviedo, I, Universidad de Sevilla, 1954, págs. 17 y sigs.

69. "El dominio público de los bienes muebles», en $R F D O, 68,1954$, páginas 7 y sigs.

70. «La organización administrativa local en la República Federal alemana», en $R E V L, 81,1955$, págs. 382 y sigs., y 82, 1955, págs. 525 y sigs.

71. "Un folleto interesante de Flórez Estrada», en $B I D E A, 24,1955$, páginas 3 y sigs.

72. «Formation et perfectionnement des fonctionnaires de l'Administration locale», en RISA, 22, 1956, págs. 155 y sigs.

73. "Criterios sobre la incompatibilidad de los funcionarios de la Administración civil del Estado según el Decreto-ley de 13 de mayo de 1955», en $R F D O, 79,1956$, págs. 463 y sigs.

74. El dominio público. Su naturaleza jurídica, Bosch, Barcelona, 1956.

75. «Problemas jurisdiccionales que suscita y resuelve la nueva Ley de la Jurisdicción Contencioso-administrativa», en REVL, 92, 1957, págs. 161 y sigs.

76. "Garantías de los ciudadanos frente a la Administración. Los Tribunales de la nueva Ley de lo Contencioso-administrativo", en $R A P, 22,1957$, páginas 229 y sigs.

77. «El silencio administrativo en la nueva Ley de la Jurisdicción Contencioso-administrativa", en BCNS, 155, 1957.

78. Tratado general de Derecho administrativo, Bosch, I (Barcelona, 1958), II (Barcelona, 1963), III (Barcelona, 1973) y IV (Barcelona, 1977).

79. «Estudio de la nueva Ley de Procedimiento administrativo», en RAP, 26, 1958, págs. 175 y sigs.

80. «El Decreto regulador de las atribuciones y deberes de los Gobernadores civiles», en $R A P, 27,1958$, págs. 165 y sigs. 
81. «Tendencia a profesionalizar el desempeño de los órganos gestores municipales», en $R E V L, 102,1958$, págs. 803 y sigs.

82. «Naturaleza jurídica de los montes públicos según la nueva Ley que los regula», en $R C D I, 31,1958$, págs. 745 y sigs.

83. "Clasificación y registro de documentos en Corporaciones locales", en $D A, 13,1959$, págs. 84 y sigs.

84. "Normas complementarias de la Ley de Procedimiesto administrativo", en $R A P, 28,1959$, págs. 84 y sigs.

85. "Garantías jurídicas de los administrados frente al Poder ejecutivo», en RISA, 26, 1960, págs. 84 y sigs.

86. Teoria y práctica de lo contencioso-administrativo. Glosas a la nueva Ley, Bosch, Barcelona, 1960.

87. "El nuevo régimen municipal de Barcelona», en $R E V L, 112,1960$, páginas 487 y sigs., y en $R I D C, 19$, Barcelona, 1962, págs. 198 y sigs.

88. «El Estado de Derecho», en Estudios jurídico-sociales homenaje al Profesor Luis Legaz Lacambra, Universidad de Santiago, 1960, págs. 827 y sigs.

89. «El Estado de Derecho y el Poder judicial independiente», en RAP, 31, 1960 , págs. 11 y sigs.

90. «Teoría del silencio administrativo», en Estudios en homenaje a Jordana de Pozas, III, 1., IEP, Madrid, 1961, págs. 129 y sigs.

91. «La especialización de los Tribunales Contencioso-administrativos», en $R A P, 35,1961$, págs. 9 y sigs.

92. «El Poder judicial independiente en cuanto a responsabilidad disciplinaria, a su responsabilidad penal y a su responsabilidad exigible por los particulares», en Problemática de la Ciencia del Derecho. Estudios en homenaje al Profesor José María Pi y Suñer, Bosch, Barcelona, 1962, páginas 77 y sigs.

93. La participación laboral en la economía y la administración de empresas y la doctrina de los Pontifices, Madrid, 1962.

94. «El problema de las incompatibilidades de los funcionarios públicos», en $R A P, 39,1962$, págs. 93 y sigs.

95. «VI Congreso Internacional de Derecho comparado celebrado en Hamburgo», en $R A P, 39,1962$, págs. 557 y sigs.

96. «La especialización en la Jurisdicción Contencioso-administrativa», en $R D A F, 1,1962$, págs. 15 y sigs.

97. «Nota sobre la naturaleza de la infracción tributaria», en $X$ Semana de Estudios de Derecho Financiero, Madrid, 1962, págs. 559-560.

98. "El silencio administrativo en el Derecho español», en Studi in onore di Silvio Lessona, Bolonia, 1963, I, págs. 43 y sigs.

99. «El cómputo del plazo para interponer el recurso de reposición previo al contencioso-administrativo", en $R A P, 41,1963$, págs. 131 y sigs.

100. La didáctica según Jovellanos, conferencia pronunciada en el Centro Asturiano de Madrid el 15 de diciembre de 1962, Madrid, 1963.

101. «Ideas sobre la revisión de la Ley de lo Contencioso-administrativo en orden a la estructura orgánica y a la competencia de sus Tribunales», en $R G L J, 1965$, págs. 383 y sigs. 
102. La independencia del Poder judicial: la especialización de los Tribunales contencioso-administrativos, IEP, Madrid, 1966.

103. «Organización administrativa de la Provincia», en el volumen colectivo La Provincia, Barcelona, 1966, II, págs. 9 y sigs.

104. «Funciones provinciales», en el volumen colectivo La Provincia, Barcelona, 1966, II, págs. 151 y sigs.

105. «VII Congreso Internacional de Derecho Comparado: Upsala, 1966», en $R A P, 51,1966$, págs. 331 y sigs.

106. El micromunicipio, comunicación al VI Congreso Hispano-Luso-Americano-Filipino de Municipios, Barcelona, 1967.

107. «Función social de la propiedad. Problemas que se plantean en la política urbanístican, en $R E V L, 157,1968$, págs. 1 y sigs.

108. "Notas históricas sobre los festejos de San Mateo y otros de Oviedo", en $B I D E A, 63,1968$, págs. 131 y sigs., y en Sociedad Ovetense de Festejos, I y II Ciclo de Conferencias sobre Oviedo, Oviedo, 1969, págs. 37 y sigs.

109. Doctrina juridica de los contratos públicos del Estado y de la Administración local, Publicaciones de la Escuela Nacional de Administración Pública, Madrid, 1969.

110. "Posible estructura orgánica y funcional de las Diputaciones Provinciales», en $R E V L, 165,1970$, págs. 1 y sigs.

111. «Servicios públicos. La empresa municipal como procedimiento de gestión del servicio local», en el volumen colectivo XIII Congreso Interamericano de Municipios (Colombia, 1970), IEAL, Madrid, 1971, págs. 237 y sigs.

112. «Problemas sobre descentralización y autonomía administrativa a nivel provincial o regional», en II Jornadas Administrativas de Galicia (Bayona la Real, 1969): Perspectivas actuales de la descentralización, Madrid, 1971, págs. 35 y sigs., y en $R D A F, 31-32,1972$, págs. 7 y sigs.

113. «Régimen administrativo de la sanidad», en Estudios en homenaje al Profesor López Rodó, II, Madrid, 1972, págs. 417 y sigs.

114. "La Región», en $R T D P, 2,1973$, págs. 710 y sigs.

115. "Política de abastecimientos en España», en el volumen colectivo Régimen jurídico del comercio interior, IEAL, Madrid, 1973, págs. 607 y sigs.

116. «La reforma de lo contenciosoadministrativo en el Proyecto de Bases de la Ley Orgánica de Justicia», en RAP, 74, 1974, págs. 299 y sigs.

117. «Tarifas de los servicios locales: licitud de la obtención de beneficios», en $R E V L, 182,1974$, págs. 289 y sigs.

118. «La revisión por las Corporaciones locales de los actos administrativos susceptibles de nulidad que hayan adoptado», en $R E V L, 183,1974$, páginas 455 y sigs.

119. “Concepto histórico del dominio público en la legislación y en la doc. trina», en Actas del III Symposium de Historia de la Administración, IEA, 1974, págs. 1 y sigs.

120. «El recurso de nulidad en la Jurisdicción Contencioso-administrativa. Su introducción en España y en los Estatutos municipal y provincial», en el 
volumen colectivo Cincuentenario del Estatuto municipal, IEAL, Madrid, 1975, págs. 433 y sigs.

121. "El dominio público de las cosas de arte y científicas», en Homenaje a Segismundo Royo-Villanova, Madrid, 1977, págs. 103 y sigs.

122. «La Junta General del Principado de Asturias y la problemática asturiana», conferencia pronunciada en el Centro Asturiano de Madrid el 15 de diciembre de 1977, en $B I D E A, 93-94,1978$, págs. 3 y sigs.

123. «El Principado de Asturias, su autonomía histórica», en $B I D E A, 98$, 1979, págs. 509 y sigs.

124. «Recensiones sobre las autonomías regionales», en Libro homenaje at Profesor Galvañ Escutia, Valencia, 1980, págs. 1 y sigs.

\section{RECENSIONES:}

José María Rodrfguez Villamil: «Legislación del Impuesto de Derechos Reales y sobre Transmisión de Bienes», 4." ed., Madrid, 1959, 582 págs., en $R A P, 29,1959$, págs. 456-457.

Alejandro NIETo: «La retribución de los funcionarios en España», Revista de Occidente, Madrid, 1967, 461 págs., en RAP, 54, 1967, págs. 532-537.

\section{TRADUCCIONES:}

Del francés:

Mirkine GuEtż́vitch: Las modernas tendencias del Derecho constitucional, Ed. Reus, Madrid, 1934.

Del alemán:

Fritz FLEINER: Derecho administrativo alemán, Ed. Labor, Barcelona, 1935. 


\section{REVISTA}

$\mathrm{DE}$

\section{JURISPRUDENCIA}


